\title{
Cognition, Persuasion and Decision Making in Older Consumers
}

\author{
CAROLYN YOON* \\ yoonc@umich.edu \\ Stephen M. Ross School of Business, University of Michigan, Ann Arbor, MI 48109-1234 \\ GILLES LAURENT* ${ }^{\dagger}$ \\ laurent@hec.fr \\ Carrefour Chair, HEC School of Management, Paris, France \\ HELENE H. FUNG \\ The Chinese University of Hong Kong \\ RICHARD GONZALEZ \\ ANGELA H. GUTCHESS \\ University of Michigan \\ TREY HEDDEN \\ Stanford University \\ RAPHAËLLE LAMBERT-PANDRAUD \\ ESCP-EAP European School of Management and Negocia, Paris \\ MARA MATHER \\ University of California at Santa Cruz \\ DENISE C. PARK \\ University of Illinois at Urbana-Champaign \\ ELLEN PETERS \\ University of Oregon \\ IAN SKURNIK \\ University of Toronto
}

Abstract

Older adults constitute a rapidly growing demographic segment, but relatively little is known about them within consumer contexts: how they process information, respond to persuasive messages, and make decisions. We discuss extant findings from consumer behavior and related disciplines (e.g., cognitive psychology, neuroscience, social psychology, gerontology) as they pertain to the effects of aging on consumer memory, persuasion and decision

\footnotetext{
* Corresponding author.

$\dagger$ The first two authors co-chaired the workshop at the Choice Symposium and made major and equal contributions to this article. The remaining authors were participants in the workshop. They also contributed to this article and are listed in alphabetical order. We wish to thank the editor and Cathy Cole for their helpful comments on the paper. The article, including a more complete list of references, was shortened to meet the page-length constraints of the special issue. The longer version is available upon request from the senior authors.
} 
making. We also identify areas for future research, particularly those with the potential to generate insights that will enhance functioning for older consumers.

Keywords: older consumers, aging, cognition, persuasion, decision making

\section{Introduction}

Older consumers represent an appreciably increasing segment of the population in developed countries, due to the aging of Baby Boomers, increasing life expectancy, and declining birth rates (Rowe and Kahn, 1998). In the U.S., those aged 65 and above are expected to be 50 million by 2010 (Polyak, 2000). Industry has responded to the growing market segment by offering a broader variety of brands, services and technologies to this group. On the one hand, the older consumers' needs are being uniquely served by many of these offerings. On the other hand, many elderly are overwhelmed and rendered more vulnerable to fraudulent and unethical marketing practices. Indeed, an increase in incidence of scams and questionable marketing tactics targeting older consumers has been widely reported (AARP Foundation, 2003).

However, there has been surprisingly limited academic research focusing on older consumers. More studies are needed to clarify the nature of age-related changes in psychological processes and to generate insights that will help older consumers function successfully in everyday life. We seek to spark interest and stimulate more theory-based research by identifying opportunities for future studies with both theoretical and practical implications. We discuss extant findings from consumer behavior and related disciplines (e.g., cognitive psychology, neuroscience, social psychology, gerontology) as they pertain to the effects of aging on consumer decision making. We are necessarily selective, and draw primarily on theory-based research that elucidates processes and mechanisms underlying age-related effects on memory, persuasion and decision making.

\section{Memory and Cognition}

The general consensus from studies of age-related changes in memory and cognition is that older adults tend to exhibit declines when compared to younger adults. Both executive functions (i.e., mechanisms for cognitive control, including those involved in working memory) and long-term memory have been implicated in cognitive decline among older adults. However, recent research suggests that for some individuals general cognitive functioning is preserved well into advanced age (e.g., Hedden and Park, 2003). Despite the variety of mental functions that decline with age, the cognitive declines of considerable magnitude documented in the laboratory do not necessarily impact everyday domains of behavior as negatively as one might expect (Zacks et al., 2000). Because the impairments in memory with age are well documented in the literature, we focus more on processes that are spared, as opposed to diminished, in older adults' executive functioning and memory. 


\subsection{Executive Functioning}

Executive functions of cognition are defined as the ability to schedule and optimize subsidiary processes. They include such subcomponents as shifting between active and inactive rules or task goals, updating the current contents of working memory to reflect task-relevance, and the inhibition or suppression of inappropriate or prepotent responses (Miyake et al., 2000). A number of studies have found that executive functions decline systematically with aging (e.g., Craik and Jennings, 1992). Recent neuroimaging evidence suggests that executive subcomponent mechanisms rely on distinct neural regions within a shared frontal-parietal network, the very same regions that are the most highly affected during the developmental processes of normal aging (Hedden and Gabrieli, 2004).

Not all older adults, however, exhibit marked declines in performance of executive function tasks. Some older adults perform nearly as well as their younger counterparts (e.g., Hedden and Park, 2003). These "successful agers" tend to be characterized by high performance on neuropsychological tasks thought to measure frontal functions (Glisky et al., 2001). For this reason, neural integrity of the frontal-parietal network and affiliated performance on executive function tasks may provide an important marker indicating which individuals are likely (or unlikely) to experience age-related declines in function. For understanding age-related changes in downstream processes such as judgments and decision making, research on executive functions may guide not only theories about which types of decision behavior are affected by aging, but also help identify individual differences in decision behavior across the lifespan.

Research on age-related differences in the subcomponents of executive functioning, and how their effects interact with intra-individual and contextual factors (e.g., health, experience, task format, time of day, culture), could lead to insights about how to maintain and improve outcomes for older consumers in the marketplace. For instance, future studies might investigate how the presentation format or other types of environmental support may result in lower susceptibility to interference effects among older adults.

\subsection{Memory}

2.2.1. Long-Term Memory Long-term memory has shown declines with age, with steady downturns apparent after the third decade of life (Park et al., 1996) in domains as varied as memory for verbal materials and faces. Age impairments are particularly large for memory of the source of information (Spencer and Raz, 1995), such as whether the information was acquired from The New York Times or in a conversation, or even whether it was internally or externally generated.

One of the primary distinctions in long-term memory is that of semantic versus episodic memory. Semantic memory comprises facts and knowledge, whereas episodic memory consists of event-based information. For example, the fact that "Carnival Cruise Lines is the world's largest cruise line" can be stored in semantic memory, but experiential details of information associated with the fact or where the fact was acquired (e.g., memory about who conveyed the information) would fall under the domain of episodic memory. Episodic 
memory, which includes memory for laboratory-based experiences, has shown age-related declines in encoding and retrieval. However, semantic memory remains more intact with age (Light, 1991).

Information that is well learned and/or highly practiced appears also to be spared with aging. Studies comparing experts in chess, aviation, typing, and piano playing report preservation of expert knowledge in older adults, with the effect being highly specific to the domain of expertise (e.g., Krampe and Ericsson, 1996).

2.2.2. Environmental Support and Compensatory Processes The degree of selfinitiated processing required by a task influences the degree of memory impairment. Recognition, in which material is re-presented and individuals identify whether or not they encountered the material previously, can be age-equivalent whereas larger degrees of impairment are seen for recall or cued recall, in which individuals must self-generate items that were previously presented.

This distinction is relevant for picture memory. Picture memory is relatively spared with age (Park et al., 1986), perhaps because of the unique, contextually-supported nature of the information. Pictures that are semantically meaningful and complex seem to be remembered equivalently by younger and older adults. These results suggest the importance of providing environmental support, such as semantically meaningful or vivid pictorial memory cues, in order to reduce the degree of effortful processing required in older adults (Craik and Jennings, 1992). The increased reliance of elderly adults on such contextual cues may suggest that they will be influenced more than younger adults by contextual variables. Thus, the framing and presentation of situations in which older adults make choices should receive special consideration.

Functional neuroimaging data highlight the possibility of substantial neural reorganization and change in the way the brain processes task information with age. The most common finding in the cognitive neuroscience of aging is that of increased bilateral activation of prefrontal regions with age (Reuter-Lorenz, 2002). Whereas younger adults may only use the left inferior prefrontal cortex for an encoding task, older adults may use both the left and the right inferior prefrontal cortex. These findings suggest that older adults may be recruiting additional resources to bolster their limited cognitive abilities and/or adopt different strategies than younger adults to process information. Functional neuroimaging may thus continue to shed light on the compensatory abilities and neural plasticity available to older adults, and play an important role in suggesting ways to remedy their poorer memory performance.

2.2.3. Meaningfulness Recent studies support the idea that socioemotional information acquires special significance with age. In a study by Rahhal et al. (2002), older adults exhibited the typical source memory decrements for which of two speakers, Mary or John, uttered a statement. However, when the information was presented in more social or emotional terms-whether the speaker was a liar or truth-teller (or "good" or "evil")—older adults' memory for the source was the same as that of the younger adults.

The results by Rahhal et al. (2002) are consistent with research showing that memory for emotional information, particularly for positive emotions, is preserved with age (Charles 
et al., 2003). Other studies have also suggested that an increased focus on emotional goals affects attention and memory. Older adults ignore negative faces in their initial attention (Mather and Carstensen, 2003) and remember a smaller proportion of negative pictures relative to positive pictures from a slide show than do younger or middle-aged adults (Charles et al., 2003). Older adults are also more likely to distort autobiographical information from fourteen years earlier in a positive direction (Kennedy et al., 2004) and remember chosen options in a more favorable light than rejected options (Mather et al., 2000). Recent work by Castel and Craik (2004) suggests that contexts supporting age-invariant memory ability extend beyond social domains, with intact recall of pricing information when prices reflect the market value but impaired memory when items are grossly over- or under-priced. These results may suggest that information must be personally meaningful and relevant to older adults in order to be successfully remembered.

\section{Persuasion}

Consumers frequently process persuasive messages in the context of specific goals or tasks. The persuasion literature has a long tradition of studying the effects of motivational factors, such as involvement, needs, and values on evaluation of messages. We discuss how motivations and goals may impact persuasion in older adults, particularly via more analytic processing modes, and how familiarity influences persuasion in older adults.

\subsection{Motivation}

Older adulthood is associated with resource limitations affecting performance on a variety of cognitive tasks. As a consequence, older consumers tend to rely more on schema-based processing while younger consumers engage in greater detailed processing (Yoon, 1997). However, these differences are moderated by time of day: older adults exhibit equivalent levels of detailed processing compared to younger adults when tested at their respective optimal times of day (in the morning for older adults, in the afternoon and evenings for younger adults).

Yoon and Lee (2004) extended these findings by investigating the implications for persuasion. They examined how older consumers' attitudes were systematically affected by motivation and ability within the Elaboration Likelihood Model (ELM) framework (Petty and Cacioppo, 1986). They find ELM effects consistent with prior results obtained on younger adults; older adults were more persuaded by cogency of a message when they had both the motivation and cognitive ability (during their optimal time of day) to process information, and by peripheral cues otherwise. Further, when presented with information about products that were high in personal relevance (e.g., health-related products vs. paper towels), motivation levels were uniformly elevated regardless of ability, and persuasion remained consistently lower.

The Yoon and Lee (2004) results suggest that older consumers are generally more skeptical about persuasive messages related to domains that carry greater risk or personal relevance-perhaps good news from a public policy perspective. Regulatory agencies and 
advocacy groups have long been concerned with the preponderance of dubious and unsubstantiated medical and health claims that target the elderly (FTC, 2002). To the extent that older consumers are less prone to persuasion when processing health-related information, it may serve to mitigate some of the potential risks and dangers that could stem from adhering to questionable claims. Greater convergent evidence with a variety of high involvement products is needed before one can be confident about these conclusions. We also need research on how motivation and ability interact to influence persuasion in older adults across different consumer domains.

\subsection{Familiarity}

When information is repeated, people tend to believe it to be more valid and believable than when it is presented once. This is the "truth effect" (Hasher et al., 1977), and older adults exhibit more pronounced susceptibility to it (Law et al., 1998). This finding has been attributed to a tendency by older adults, relative to younger adults, to have poorer source or context memory but relatively intact familiarity for a repeated claim.

This bias among older adults to think that information they have seen before is true (the "illusion of truth," Begg et al., 1992) may have consequences for their ability to distinguish true from false claims. It may interfere with consumers' need to sort through potentially true and false information when purchase decisions require reliance on sources that vary widely in credibility, such as Consumer Reports versus paid advertisements, tabloids, or websites with authors of unknown expertise. Skurnik et al. (2005) found that trying to discredit false information that is already familiar can in fact backfire and paradoxically increase belief in its truth, and older consumers are particularly susceptible to this effect.

A major drawback of an increasing flood of information available to consumers is that it can be more difficult to sort through and remember. Although it may be quite adaptive at times to rely on familiarity to make consumer judgments, it can also increase the likelihood of undesirable outcomes for older adults who do not have sufficient motivation or ability to scrutinize the incoming information. It may be crucial in such circumstances to provide older adults with environmental support, such as written materials (e.g., Morrow et al., 1999) or visual imagery (Israel and Schacter, 1997) to supplement or improve memory. Additional research should explore situations in which older consumers are less susceptible to the bias, especially when recollection of context is needed to establish truth. A possible direction for future research is to generate insights about helping older adults to encode and retain the original context.

\subsection{Emotional Goals}

According to the socioemotional selectivity theory proposed by Carstensen and colleagues (e.g., Carstensen et al., 1999), as people age, they are more motivated by goals aimed at deriving emotional meaning from life relative to goals that increase future preparedness. The memory and persuasion literatures suggest that people are more likely to remember (e.g., Blaney, 1986) and to be persuaded by messages that are more goal-relevant (e.g., Clary et al., 
1994). Together, these research streams imply that, compared to other types of messages, those that are emotionally relevant are particularly appealing to older adults. Fung and Carstensen (2003) found that, relative to younger adults, older adults remembered a higher proportion of information from an advertisement appealing to emotionally meaningful goals over those appealing to knowledge goals or with a neutral appeal. Williams and Drolet (2005) obtained results indicating age-related preference and memory for emotional versus rational appeals.

Fung and Ching (2004) asked older adults to read pamphlets that promoted healthy eating with identical factual information but highlighting different goals. The message that emphasized eating healthily to protect the ones we love was evaluated more positively and better remembered by older adults compared to the ones that emphasized eating healthily for personal achievement or for factual health benefits. Results suggest that whereas older adults are more likely to prefer, remember, and be persuaded by messages with emotional appeal than messages with non-emotional appeal, younger adults do not show such biases.

Additional research is needed to gain a better understanding of the consequences associated with age-related differences in processing of emotional information. For instance, the bias for emotional information may render older adults more prone to source misattributions for experienced emotions. Future studies might examine the degree to which emotional goals can compromise older consumers' memory in contexts requiring processing of factual details.

\section{Decision Making}

While the literature on both basic and applied research on judgment and decision making is very large and diverse, studies on age-related changes in decision processes have only recently begun to receive attention (Peters et al., 2000). We now consider some general patterns of findings in domains related to aging and decision making.

\subsection{Decision and Risk Avoidance}

Although stereotypes about the elderly suggest cautiousness in their attitudes toward risk, findings about real-world behavior suggest that they evaluate risk similarly to younger adults. Older adults are, however, potentially more likely to avoid making decisions by postponing or delegating them. When faced with medical decisions, older adults were more prone than younger adults to indicate that they would rather not make the decisions themselves, instead leaving them up to a doctor (Steginga and Occhipint, 2002). More generally, in solving interpersonal dilemmas (e.g., what a father should do about a 16-year old daughter who repeatedly takes his car) older adults were more likely to use avoidant strategies, whereas younger adults preferred problem-focused action (Blanchard-Fields et al., 1995). But, as the emotional salience of the problems increased, younger adults' strategies became more like those of older adults.

In the short run, people generally feel better after deciding not to make a decision in high-conflict situations - and they feel better than people who actually made a choice (Luce, 
1998). Thus, one way to avoid negative affect is to avoid difficult decisions. In the long run, however, there are downsides to this approach as avoiding decisions when action is necessary may lead to serious negative consequences. Future research is needed to identify remedial measures that may help older adults to overcome avoidance tendencies in potentially serious situations.

\subsection{Information Search}

Older adults seem to seek less information than younger adults when making decisions or solving problems. For example, Streufert et al. (1990) recruited mid-level managers to participate in an all-day group decision simulation and found that teams composed of older managers made fewer requests for additional information than younger teams. Similar patterns emerge in studies of medical decisions (Ende et al., 1989) and car purchases (Lambert-Pandraud et al., 2005). This reduced level of information seeking may stem from lower working memory capacity. Alternatively, older adults (like experts) may use their experience to choose and process relevant information more effectively (Meyer et al., 1995).

That older adults seek less information overall is not necessarily problematic. Information needs to be useful and usable. Without usable information and an adequate understanding of choices and the implications of choices, consumers can feel dissatisfied and far less than empowered. The challenge is not merely to communicate voluminous amounts of information but to understand how to present and target accurate information so that it is actually used in decisions (Hibbard and Peters, 2003). One avenue for future research is to consider how emotional goals may aid or hinder efficacious information search. Mather et al. (2005) found that older adults' increased focus on emotional goals led to more time spent on examining positive (as opposed to negative) information about decision options.

\subsection{Heuristics and Biases}

Some researchers have recently suggested that the standard biases documented in the literature (Tversky and Kahneman, 1983) do not necessarily reflect shortcomings but just the opposite, and that the biases emerge because people spend too much time, or devote too much cognitive resources, to thinking and reasoning (Liu et al., 2004; cf. Mutter and Pliske, 1994). For instance, in the standard baserate neglect paradigm, the person overthinks reasons about the scenario, which swamps the simple baserate information that is present in the problem.

According to the availability heuristic, when judging frequency, people use the ease with which examples can be drawn to mind as a cue. The cognitive shortcoming view would suggest that with diminished cognitive resources, say, due to aging, the use of this heuristic should increase. However, the alternate view that the heuristic is more about how people think too much leads to the opposite prediction with age-the more diminished cognitive resources resulting from aging will lead to less reliance on the cue. Consistent 
with this reasoning, Liu et al. (2004) found that older adults make less use of the availability heuristic than younger adults. Individual differences in cognitive capacity appeared to support their interpretation so that individuals with greater capacity used the heuristic more. In another line of work they also showed that older adults were less susceptible to the conjunction error. These results are intriguing and more studies are clearly needed on whether aging is accompanied by lower susceptibility to the standard heuristics and biases.

\subsection{Choice}

The choice process can be quite complex. In choice situations where preferences are unstable, consumers may need to use comparative information. Thus, they must be able to take in and process the information, correctly interpret it, identify the important factors to integrate into a decision, weigh them so as to match the individual's needs and values, make trade-offs, and bring all the factors together into a choice. A key implication is that when people must sort through complex, unfamiliar, and important factors to make a choice, how that information is framed and packaged will to a large degree determine what information is attended to and used.

Hibbard and Peters (2003) suggested three processes to enhance the use of comparative information that may be particularly important to older adult consumer choices. They provide evidence suggesting that comprehension, motivation, and the actual use of the information are increased when cognitive effort is reduced, when the decision maker is moved closer to the actual experience, and when the meaning of information is highlighted for the decision-maker. Their findings suggest that reduced cognitive effort is not necessarily associated with negative consequences for older adults; the decision effects may in fact be positive in some situations.

Not all choices, rely on extensive cognitive processes. We might, for instance, expect choices to be consistent with preferences in situations that involve habitual ways of making judgments. However, almost nothing is known thus far about the extent to which preference structures vary or remain stable across the lifespan.

As people age, they are likely to find that the use of affect is particularly effective in making choice decisions. Work by Damasio and colleagues (e.g., Bechara et al., 1996) suggests that affective reactions to experiences with an object drive the learning of integral affect or somatic markers - an anticipatory affective (and physiological) response- that subsequently guides choices. Thus, learning to choose involves affective, rather than deliberative, mechanisms. Hence, we might expect that a lifetime of learning will increase older adults' propensity to allow their choices to be guided more by affect versus controlled cognitive processes. Studies are needed to ascertain the conditions under which affect may lead to desirable versus inappropriate choices. With respect to undesirable choices, future research should identify interventions that offer the potential to restrain or prevent poor consumer decisions among older adults.

Despite the wealth of knowledge about judgment and decision making, we know very little about these processes among older adults. Most empirical evidence to date has been gathered 
from studies conducted on younger adults that may not generalize to older consumers. Thus research on choice processes, and on judgment and decision making processes in general, are crucial areas for future research.

\section{Public Policy Issues}

Public policy concerns further fuel the need for research on older consumers. Older consumers are among the most vulnerable targets of scams. The U.S. Federal Trade Commission (1999-2001) reports that a disproportionate number of consumer fraud victims, some 80 percent or more, are 65 or older. Interviews with officials in the French ministry in charge of consumer protection (personal communication, April 2004) provided numerous examples of this phenomenon of elder abuse. For example, there have been many incidences of older adults purchasing expensive but unnecessary goods and services, such as purchasing a complete electric installation when replacing a fuse wire would have been sufficient. Cognitive decline, reduced information seeking, a tendency to avoid making a decision for oneself, and delegating decisions to people posing as experts are some tentative explanations for vulnerability to deceptive marketing practices. A better understanding of the psychological mechanisms involved in elder abuse would thus be a basis for more effective regulation, prevention, correction, and sanction.

There are two particularly interesting avenues for future research. First, older adults are often unaware that they have been victimized. What are the factors that lead older persons not to realize they are the victims of scams (many of which would remain undiscovered without intervention from the victims' relatives or friends)? Second, what are the reasons that older victims prefer not to report scams even when they are aware of them? What are the main deterrents (e.g., fear of embarrassment, loss of legal rights, and/or placement in a nursing home) and how might they be best addressed?

In France, like in many other countries, older people are protected by "abuse of weakness" regulations. However, the definition of "weakness" is somewhat imprecise, and a theorybased set of reliable criteria, relying on recent research, would be most useful. This is all the more the case as unethical individuals and organizations have undoubtedly developed their own sets of criteria for identifying potential victims. Moreover, theory-based criteria are also needed for assessing which marketing and sales techniques are appropriate for older consumers.

\section{Conclusion}

We have briefly reviewed some of the major findings on memory, persuasion and decisionmaking as they related to older consumers. Although much progress has been made in terms of generating important insights with respect to older adults in cognitive domains, a great deal more research is needed to understand the effects of aging on more downstream consequences such as persuasion and decision-making. In particular, research efforts are needed to generate a systematic understanding of contextual factors that interact with age to affect older consumers' judgments and behaviors. Factors that enable older consumers 
to function well may then lead to promising interventions and improvements to aid them in their decisions.

\section{References}

AARP Foundation. (2003). "Off the Hook: Reducing Participation in Telemarketing Fraud," http://www.aarp.org/research/frauds-scams/telemarketing/aresearch-import-179-D17812.html.

Bechara, Antoine, Daniel Tranel, Hanna Damasio, and Antonio R. Damasio. (1996). "Failure to Respond Autonomically to Anticipated Future Outcomes Following Damage to Prefrontal Cortex," Cerebral Cortex 6, 215-225.

Begg, Ian M., Ann Anas, and Suzanne Farinacci. (1992). "Dissociation of Processes in Belief: Source Recollection, Statement Familiarity, and the Illusion of Truth,” Journal of Experimental Psychology: General 121, 446-458.

Blanchard-Fields, Fredda, Heather Casper Jahnke, and Cameron Camp. (1995). "Age Differences in ProblemSolving Style: The Role of Emotional Salience," Psychology and Aging 10, 173-180.

Blaney, Paul H. (1986). "Affect and Memory: A Review," Psychological Bulletin 99, 229-246.

Carstensen, Laura L., Derek M. Isaacowitz, and Susan Turk Charles. (1999). "Taking Time Seriously: A Theory of Socioemotional Selectivity," American Psychologist 54, 165-181.

Castel, Alan D., and Fergus I. M. Craik. (2004). "Memory for Numerical Information in Younger and Older Adults: The Role of Schematic Support," Poster presented at the 10th Cognitive Aging Conference, Atlanta, Georgia.

Charles, Susan Turk, Mara Mather, and Laura L. Carstensen. (2003). "Aging and Emotional Memory: The Forgettable Nature of Negative Images for Older Adults," Journal of Experimental Psychology: General 132, 310-324.

Clary, E. Gil, Mark Snyder, Robert D. Ridge, Peter K. Miene, and Julie A. Haugen. (1994). "Matching Messages to Motives in Persuasion: A Functional Approach to Promoting Volunteerism," Journal of Applied Social Psychology 24, 1129-1149.

Craik, Fergus I. M., and Janine M. Jennings. (1992). "Human Memory.” In Fergus I. M. Craik and Timothy A. Salthouse (eds.), The Handbook of Aging and Cognition Hillsdale, NJ: Lawrence Erlbaum Associates, pp. 51110.

Ende, Jack, Lewis Kazis, Arlene Ash, and Mark A. Moskowitz. (1989). "Measuring Patients' Desire for Autonomy: Decision Making and Information-Seeking Preferences Among Medical Patients," Journal of General Internal Medicine 4, 23-30.

Federal Trade Commission Staff Report. (2002). "Weight Loss Advertising: An Analysis of Current Trends," http://www.ftc.gov/opa/2002/09/weightlossrpt.htm.

Federal Trade Commission Staff Summary. (1999-2001). "Activities Affecting Older Americans," http://www3.ftc.gov/os/2001/10/agingrpt.htm.

Fung, Helene H., and Laura L. Carstensen. (2003). "Sending Memorable Messages to the Old: Age Differences in Preferences and Memory for Advertisements," Journal of Personality and Social Psychology 85, $163-178$.

Fung, Helene H., and B. H. Ching. (2004). Age Differences in Goals: Its Implications for Health Promotion. Manuscript in preparation.

Glisky, Elizabeth L., Susan R. Rubin, and Patrick S. R. Davidson. (2001). "Source Memory in Older Adults: An Encoding or Retrieval Problem," Journal of Experimental Psychology: Learning, Memory, and Cognition 27, 1131-1146.

Hasher, Lynn, David Goldstein, and Thomas Toppino. (1977). "Frequency and the Conference of Referential Validity," Journal of Verbal Learning \& Verbal Behavior 16, 107-112.

Hedden, Trey, and John D. E. Gabrieli. (2004). "Insights into the Ageing Mind: A View from Cognitive Neuroscience," Nature Reviews Neuroscience 5, 87-96.

Hedden, Trey, and Denise C. Park. (2003). "Contributions of Source and Inhibitory Mechanisms to Age-Related Retroactive Interference in Verbal Working Memory," Journal of Experimental Psychology: General 132, 93112. 
Hibbard, Judith H., and Ellen Peters. (2003). "Supporting Informed Consumer Health Care Decisions: Data Presentation Approaches that Facilitate the Use of Information in Choice," Annual Review of Public Health 24, 413-433.

Israel, Lana, and Daniel L. Schacter. (1997). "Pictorial Encoding Reduces False Recognition of Semantic Associates," Psychonomic Bulletin \& Review 4, 577-581.

Kennedy, Quinn, Mara Mather, and Laura L. Carstensen. (2004). "The Role of Motivation in the Age-Related Positivity Effect in Autobiographical Memory," Psychological Science 15, 208-214.

Krampe, Ralf T., and K. Anders Ericsson. (1996). "Maintaining Excellence: Deliberate Practice and Elite Performance in Younger and Older Pianists," Journal of Experimental Psychology: General 125, 331-359.

Lambert-Pandraud, Raphaelle, Gilles Laurent, and Eric Lapersonne. (2005). "Repeat-Purchasing of New Automobiles by Older Consumers: Empirical Evidence and Interpretations," Journal of Marketing 69, 97 113.

Law, Sharmistha, Scott A. Hawkins, and Fergus I. M. Craik. (1998). "Repetition-Induced Belief in the Elderly: Rehabilitating Age-related Memory Deficits," Journal of Consumer Research 25, 91-107.

Light, Leah L. (1991). "Memory and Aging: Four Hypotheses in Search of Data," Annual Review of Psychology $42,333-376$

Liu, Linda Hand, Richard Gonzalez, and Denise C. Park. (2004). Judgment and Decision Making in Older Adults Manuscript in preparation.

Luce, Mary Frances. (1998). "Choosing to Avoid: Coping with Negatively Emotion-laden Consumer Decisions," Journal of Consumer Research 24, 409-433.

Mather, Mara, and Laura L. Carstensen. (2003). "Aging and Attentional Biases for Emotional Faces," Psychological Science 14, 409-415.

Mather, Mara, Marissa Knight, and Michael McCaffrey. (2005). "The Allure of the Alignable: False Memories of Choice Features," Journal of Experimental Psychology: General 134, 38-51.

Mather, Mara, Eldar Shafir, and Marcia K. Johnson. (2000). "Misrememberance of Options Past: Source Monitoring and Choice," Psychological Science 11, 132-138.

Meyer, Bonnie J. F., Connie Russo, and Andrew Talbot. (1995). "Discourse Comprehension and Problem Solving in an Ill-structured Domain: Decision About the Treatment of Breast Cancer by Women Across the Life Span," Psychology and Aging 10, 84-103.

Miyake, Akira, Naomi P. Friedman, Michael J. Emerson, Alexander H. Witzki, Amy Howerter, and Tor D. Wager. (2000). "The Unity and Diversity of Executive Functions and Their Contributions to Complex "Frontal Lobe" Tasks: A Latent Variable Analysis," Cognitive Psychology 41, 49-100.

Morrow, Daniel G., Von O. Leirer, Lisa M. Carver, Elizabeth Decker Tanke, and Allison D. McNally. (1999). "Repetition Improves Older and Younger Adult Memory for Automated Appointment Messages," Human Factors 41, 194-204.

Mutter, Sharon A., and Rebecca M. Pliske. (1994). "Aging and Illusory Correlation in Judgments of Cooccurrence," Psychology and Aging 9, 53-63.

Park, Denise C., J. Thomas Puglisi, and Anderson D. Smith. (1986). "Memory for Pictures: Does an Age-Related Decline Exist?" Psychology and Aging 1, 11-17.

Park, Denise C., Anderson D. Smith, Gary Lautenschlager, Julie L. Earles, David Frieske, Melissa Zwahr, and Christine L. Gaines. (1996). "Mediators of Long-term Memory Performance Across the Life Span," Psychology and Aging 11, 621-637.

Peters, Ellen, Melissa L. Finucane, Donald G. MacGregor, and Paul Slovic. (2000). "The Bearable Lightness of Aging: Judgment and Decision Processes in Older Adults," In National Research Council, Paul C. Stern \& Laura L. Carstensen (eds.), The Aging Mind: Opportunities in Cognitive Research (Appendix C). Washington, DC: National Academy, pp. 144-165.

Petty, Richard E., and John T. Cacioppo. (1986). Communication and Persuasion: Central and Peripheral Routes to Persuasion. New York: Springer-Verlag.

Polyak, Ilana. (2000). “The Center of Attention,” American Demographics 22 (November), 30-33.

Rahhal, Tamara, Cynthia P. May, and Lynn Hasher. (2002). "Truth and Character: Sources that Older Adults can Remember," Psychological Science 13, 101-105.

Rowe, John W., and Robert L. Kahn. (1998). Successful Aging. New York: Pantheon Books. 
Reuter-Lorenz, Patricia A. (2002). "New Visions of the Aging Mind and Brain," Trends in Cognitive Sciences 6, 394-400.

Skurnik Ian, Carolyn Yoon, Denise C. Park, and Norbert Schwarz. (2005). "How Warnings About False Claims Become Recommendations," Journal of Consumer Research 31, 713-724.

Spencer, Wesley D., and Naftali Raz. (1995). "Differential Effects of Aging on Memory for Content and Context: A Meta-analysis," Psychology and Aging 10, 527-539.

Steginga, Suzanne K., and Stefano Occhipinti. (2002). "Decision Making About Treatment of Hypothetical Prostate Cancer: Is Deferring a Decision an Expert-opinion Heuristic?” Journal of Psychosocial Oncology 20, 69-84.

Streufert, Siegfried, Rossanne Pogash, Mary Piasecki, and Gerald M. Post. (1990). "Age and Management Team Performance," Psychology and Aging 5, 551-559.

Tversky, Amos and Daniel Kahneman. (1983). "Extensional Versus Intuitive Reasoning: The Conjunction Fallacy in Probability Judgment," Psychological Review 90, 293-315.

Williams, Patti and Aimee Drolet. (2005). "Age-related Differences in Responses to Emotional Advertisements," Journal of Consumer Research (forthcoming).

Yoon, Carolyn. (1997). “Age Differences in Consumers' Processing Strategies: An Investigation of Moderating Influences," Journal of Consumer Research 24, 329-342.

Yoon, Carolyn and Michelle P. Lee. (2004). "Persuasion Implications of Age-related Differences in Consumer Processing: The Effects of Motivation and Ability," Working Paper, University of Michigan.

Zacks, Rose T., Lynn Hasher, and Karen Z. H. Li. (2000). "Human Memory.” In Fergus I. M. Craik and Timothy A. Salthouse (eds.), The Handbook of Aging and Cognition ( $2^{\text {nd }}$ ed.). Mahwah, NJ: Lawrence Erlbaum Associates, pp. 1-90. 